\begin{tabular}{l|c|c} 
Journal of Social Studies Education Research & \\
Sosyal Bilgiler Eğitimi Araştırmaları Dergisi & 2017:8 (2), 130-144
\end{tabular}

\title{
Newest Web-Technologies for Studying and Diagnosing Individual Abilities of Learners
}

\author{
Yuliya S. Nikolaeva ${ }^{1}$, Nikolay I. Pak ${ }^{2}$
}

\begin{abstract}
The relevance of the research is due to the need of taking into account the learners' cognitive characteristics in the educational process. Knowing the personal qualities of people is also important when choosing an occupation or employment. This is why the paper is aimed at describing the opportunities of the newest Web and mobile applications for studies and self-diagnostics of users based on the cloud technology of diagnosing the human individual and cognitive abilities. The leading approach to studying this problem is the projective and recursive strategy that allows viewing the problem of expert statistics accumulation and user diagnostic results analysis in an integrated way. The paper presents the developments in problem-solving computer environments for diagnosing human individual and integrated abilities. Grounds are given for diagnostics of the main human cognitive abilities: the scope of memory and attention; information processing, reading, typing speeds and others. The website for developing the new diagnostics and conducting studies can be accessed by everyone with any browser via http://selftest.ufoproger.ru. The website has been developed by the university students under the guidance of professor N.I. Pak. The materials of the paper are of practical value for teachers designing the educational process up to the learners' individual characteristics.
\end{abstract}

Keywords: Web-diagnostics, self-diagnostics, cognitive abilities, assessment, training, individualization, giftedness.

\section{Introduction}

Objective diagnosing of cognitive characteristics is extremely important for ensuring the efficiency of any educational and upbringing process - from preschool upbringing up to the adult education. The methods (Klahr \& Li, 2005, Koedinger \& Aleven, 2007) of psychological and pedagogical diagnostics that are available in cognitive science have not turned systemic and mass scale so far. Currently there are various websites for diagnosing human individual cognitive characteristics (Auvinen et al., 2015, Bloom, 1956, Diamond, 2002) but they have no opportunities for conducting integrated studies and no broad consumer qualities for learners, teachers and educational process at educational institutions (Gentner et al., 2001, Goswami, 2001, Ines Reyes-Cespedes \& Dominguez-Claro, 2015).

${ }^{1}$ Assoc. Prof., Candidate of Engineering, Krasnoyarsk State Pedagogical University named after V.P. Astafyev, nikolaeva_y_s@mail.ru

${ }^{2}$ Prof., Doctor of Pedagogy, Head of the Department, Krasnoyarsk State Pedagogical University named after V.P. Astafyev, nik@kspu.ru 
The abilities diagnosing problems have never ceased to be relevant. The problems were acute for both Soviet and post-Soviet researchers as well. The diagnosing tests being developed (Clique, 1984, Nayser, 1981, Teplov, 1961) were applied not everywhere and not always due to poor technical capacities for information processing. As of today, the lack of accessible, targeted and highly motivated technologies for repeatedly self-diagnosing one's own cognitive abilities considerably hinders the prompt detection of giftedness and cognitive characteristics variation in children, the successful vocational guidance for youth, and selection of the appropriate methods and training tools for adults. These problems are critical in quite a special way for today's Russia under its upgrade of education. For example, this is the problem of creating elite schools and other educational institutions for gifted children. The modern Russian school sees the trend of earlier diagnosing the "special" abilities and inclinations of students becoming increasingly widespread. Starting virtually from the first year of schooling, they find out what the schoolchildren are keen on - the humanities or the natural sciences. The objective diagnostics of cognitive abilities of youth is important for the vocational guidance emphasis of their education as well as for their teachers in order to correct and develop the required cognitive characteristics ensuring the success of personality. As for adult education, this can be rendered more efficient by selecting the training techniques that are relevant to the adults' cognitive abilities.

The objective of the work is to develop a cloud technology of diagnosing the human cognitive abilities and to create a Web and mobile application for the users' statistical studying, standardizing and self-diagnosing on its basis.

\section{Literature Review}

The scientific and technical advance in cloud technologies (Murillo \& Hernandez-Castilla, 2015, Nath \& Szücs, 2014) and research of mind allows creating systems that feature high intellectualization and automation of personal cognitive abilities diagnosing and development processes (Jain et al., 2014, Jong, 2016, Karpov, 1964, Konopkin, 1980) of innovative character (Tarman, 2016). The information model of thinking and the adopted mechanisms of cognitive processes rely on the theory suggested by Nayser (1981). Another work (Lishin et al., 1990) demonstrated a successfully completed project of creating a digital "smart" teacher - Hyperbrain - which is capable of not only sending messages on studying to the learners but also transferring the experience based on the mental schemes platform. The relevance of creating an artificial collective mind as a knowledge cloud consists in the opportunities for expanding the resources of 
brain, its teaching and cognitive abilities. The most useful aspect in the practical employment of such artificial educational mind is diagnosing and developing the thinking as a whole and its individual components in particular (Bazhenova \& Pak, 2016).

In the Soviet time, the problems of thinking, cognitive abilities and giftedness diagnostics were studied by a number of scholars (Nayser, 1981, Kholonaya, 2000, Teplov,1961) and others.

At those times, diagnosing was mainly performed using the psychological tests developed by the Soviet scholars (Kholonaya, 2000, Teplov, 1961). The majority of tests were conducted "manually", without computers, which hindered both the performance and processing of the results.

The psychological diagnostics of a personality's cognitive conditions are difficult to formalize, and sometimes they cannot be - due to the lack of relevant modeling for cognitive mechanisms. With regard to this, the most widespread way of solving the problem of computer diagnostics of human psychological and physical characteristics are expert and statistical methods (Rassel \& Norvig, 2006). At present exist various diagnosing websites (Gentner at al., 2001, Goswami, 2001, Ines Reyes-Cespedes \& Dominguez-Claro, 2015) and technologies (Krutka \& Carano, 2017) for human individual cognitive characteristics (Auvinen et al., 2015, Bloom,1956, Diamond, 2002) where one can get diagnosed using various tests. The result of doing these tests is usually a static characteristics of a person determined by special keys. However, they do not focus on research done by the users themselves, while this is extremely important for self-analysis and decision making. For teachers, the research nature of the learners' cognitive abilities diagnosing procedures is especially valuable (Waters \& Russell, 2016; Cowgill II \& Waring, 2017). Hence the diagnosing websites have to be open, practice-oriented and of a projective character (Pak, 2014, Pak, 2015).

\section{Methodological Framework}

The study is based on the projective and recursive strategy (Pak, 2014) of creating a software product for collective and distributed research and practice-oriented user activity based on a cloud platform. The normal reference cognitive characteristics are objectified on the basis of expert and statistical analysis methods as well as dynamic testing ones (Philipp et al., 2015, Richland et al., 2007). The project is targeted at detecting two categories of abilities. The first one is associated with the principal cognitive characteristics (Richland et al., 2015, Tarling \& Ng'ambi, 2016, von Aufschnaiter et al., 2015, Wiegner \& Willms, 1991, Wineburg, 1991, Zhang 
et al., 2015) having already become traditional for people. It includes the scope of attention, the speed of calculation operations, reading, constructing actions etc. The second category deals with assessment and development of combined abilities: the level of learning, the speed of learning, the ability to work under limited information and time resources etc. It also involves finding out the abilities for the humanities and for the exact sciences.

First of all, the structure and composition of human cognitive abilities that are analyzable by average statistics was determined and the concept of cloud technology for the diagnostic toolkit was developed.

An initial set of diagnostics for machine-assisted realization of them in conditions of a Web interface was selected, with problem-solving environments and diagnostic toolkit developed.

To give an example, the following diagnostics were included into the basic composition of the first category:

- The scope of attention is measured with the help of a sequence of alternating numbers and a PC game "Paired cards";

- The operational thinking speed is diagnosed by taking down the time of performing the arithmetic actions;

- The speed of reading is determined by the quantity of words per unit time, with the ratio of understanding taken into account;

- The speed of typing is registered by the time of creating a set text.

Diagnostics of the second category are targeted at assessment and development of the combined abilities, in particular:

1. The level of learning is calculated using the total feedback coefficient as described in the cited work (Nikolaeva, 2012).

2. The speed of learning is calculated using the total feedback coefficient behavior curve (Nikolaeva, 2010). The curve allows seeing how quickly the process of learning occurs for each learner individually.

3. The optimum time of work under the time resource limit. The optimum time is one for which a learner performs tasks solving activity without mistakes at a timing convenient for the learner.

4. The learning activity under the actions resource limit (Nikolaeva, 2012). 
In order to solve a task, one has to perform a certain quantity of actions resulting in solving the task. The value is reduced as learning proceeds. So, for solving a task, a limited resource of actions one can use when solving the task is created. For solving each task, the learner gets a certain resource of actions. According to the equal cost model (Novikov, 1998), each correct or incorrect action of the learner while solving the task reduces the value by one unit. The learner has to minimize spending of the resource, i.e. to find the optimum activity paths of searching for the target condition during the process of learning.

\section{Results and Discussion}

As of now, the website https://self-test.ufoproger.ru/ and a mobile application have been created for studies and diagnostics by human individual cognitive abilities. The diagnostics described in the previous sections have been implemented both in software and in the Web environment.

The website presents diagnostics subdivided into categories:

1. General. These self-diagnostics can be used by an average person.

2. For children. These self-diagnostics are for primary school students.

3. Difficult. Here the advanced difficulty assignments are collected.

All categories employ the following procedures:

- Calculation of simple expressions - one has to perform assignments for addition, subtraction and multiplication operations against the clock;

- Jigsaw puzzles - against the clock, one has to put together visual images of the set pictures;

- Paired cards - one has to find paired cards in a large total of cards, with only two of them to be opened at once;

- Sequences - a sequence of digits has to be memorized, commencing with two digits, with one more added to the sequence at each stage;

- Simple arithmetic - multiplication and addition of two-digit and three-digit numbers;

- Text work - assessment of the speed of typing (one has to type a set text in a certain time without mistakes) and of reading (one has to read the text and answer the questions). Currently there are over one hundred users on the website. All protocols of diagnostics (over two thousand of them) are stored in a special database for conducting the expert and statistical research. Here are some examples of data that can be retrieved using the existing database: 
1. The "Scope of attention" studies ("Sequences" diagnostics) have shown that mainly the tested ones can remember a sequence of 3 symbols (28\%). The highest quantity of symbols memorized by some testees is 8 symbols $(10 \%)$.

2. The "operational thinking speed" cognitive characteristics was studied using the "Simple arithmetic" diagnostics. While analyzing the data obtained, it can be seen that different age groups show different operational thinking speed. With the younger than 18 age group, the average quantity of correct mathematical operations per minute makes around 15,32 correct operations per minute. It is 9,56 operations with those aged 18-25 and 5,3 operations with the 2540-year-old group. The age group of over 40 years old figure is 4 operations per minute.

3. The "constructing abilities" cognitive characteristics is diagnosed using the "Jigsaw puzzles" game. In the age group of under 18, the time of putting the puzzles together is about 24,6 sec., in that of 18-25 years old - 31,9 sec. It is 43,4 sec. with those aged 25-40 and 80,7 sec. with ones older than 40 .

4. The "scope of attention" cognitive characteristics is diagnosed using the "Paired cards" game. Four age groups have been considered. Notably, with those under 18 years old, the scope of attention makes roughly 45,8 pairs seen per minute. With the group aged 18-25, it is 71 pairs and with the group aged 25-40, the scope of attention counts 65 pairs. 63 pairs per minute are seen by those older than 40 .

5. The "speed of reading" diagnostics has shown (Fig. 1) that the average reading speed is higher in men (206 words/minute) than in women (159 words/min).

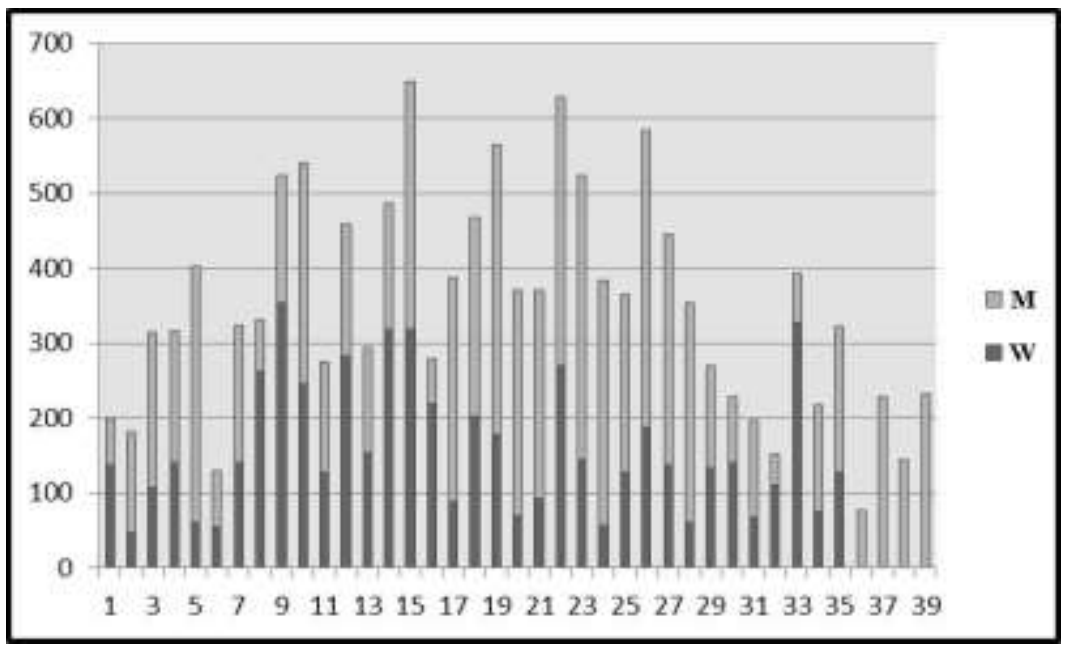

Figure 1. Distribution according to the "Speed of reading" diagnostics. The quantity of the tested ones is along the horizontal axis, the quantity of words per minute - along the vertical one. 
The "typing speed" diagnostics has found a high typing speed with people aged 18-25 (Fig. 2).

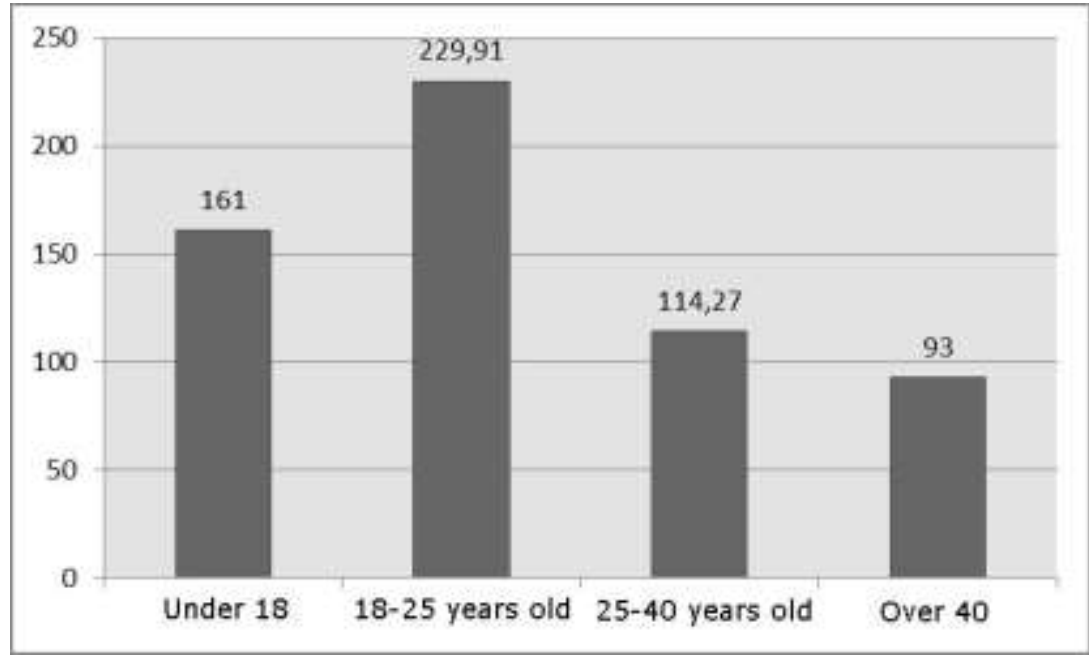

Figure 2. Distribution according to the "Typing speed" diagnostics. The age of the tested ones is along the horizontal axis, the quantity of words per minute - along the vertical one.

In order to diagnose the level and speed of learning (Diyachuk et al., 2010, Bortnovskiy \& Diyachuk, 2011), the optimum time of work and learning activity under the limited information resources, systems for automatic management of the learners' activity were designed. The automatic management systems allow controlling the learners' task solving against time resource limit and the limit of possible actions in verbal and algorithmic problem-solving environment (Nikolaeva, 2010). They meet two requirements: first, the managing actions are aimed at forming the learners' behavior which allows obtaining the task solution; second, the interaction of learners and control center is that for achieving a useful result, i.e. error-free task solving.

For processing the experimental data obtained during abilities diagnosing, a computer system of processing the learners' activity products. Using this, various factors influencing the process of learning activity are studied (Bush \& Mosteller, 1962).

When working in problem-solving environments, learners perform actions that are subsequently analyzed with stored man-machine communication protocols.

Data were obtained characterizing the learners' activity: the level of learning, the speed of learning, the optimum time of work and learning activity under the limited information resources (Nikolaeva, 2010). Figure 3 shows learning curves in the scale of assignments completed. As a result of calculations, the speed of learning was obtained individually for each learner. 

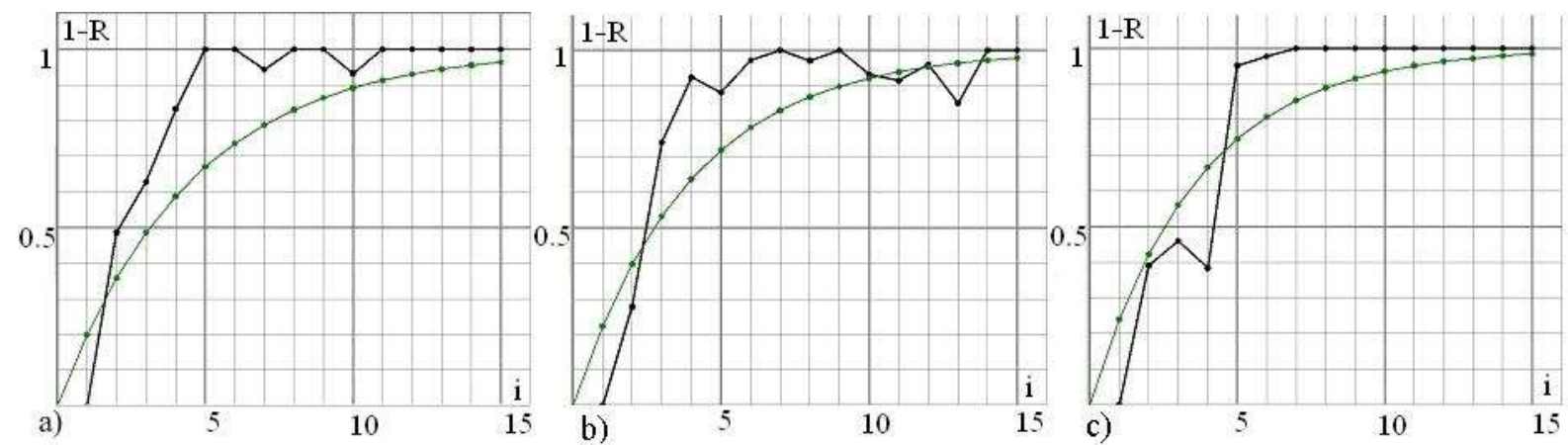

Figure 3. The speed of learning in the scale of assignments completed: a) Learner 1; b) Learner 2 ; c) Learner 3.

The characteristics of the optimum task solving activity time in problem-solving environments were obtained. After processing of the data, it is clear that the activity time is reduced with each following assignment completed getting close to the optimum one. The parameter will be individual for each learner. By studying the quality dependence, one can judge about the character of the learners' activity.
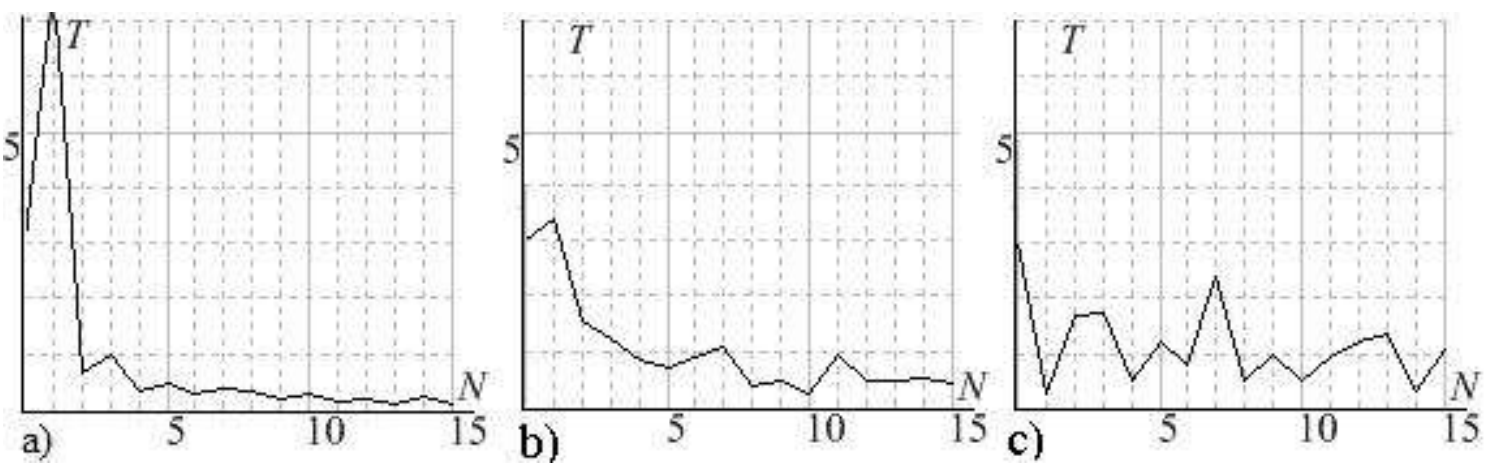

Figure 4. Work timing during task solving: a) of learner 1; b) of learner 2; c) of learner 3. (N is the number of assignment and $\mathrm{T}$ is the time resource in minutes).

It is clear from the graph in Fig. 4a that after completion of five assignments the time resource has settled at approximately the same value $-0,1$ minute. With learner 2 , the time resource has reached the value of 0,5 minute after 10-12 assignments (see Fig. 4b), while the total of 15 assignments failed to bring learner 3 to the optimum work time (Fig. 4c).

The variation of work tempo shown in Fig. 4 is explained by the students' oscillating attention during the learning activity. In particular, the work tempo variations of tested ones 1, 2 and 3 differ essentially in the amplitude and damping rate. The work tempo variation amplitude remained almost unchanged for tested one 3. The experiment has shown that a higher work rate is accompanied by the change of the cognitive component place in the structure of activity. 
The individual characteristics of learners were obtained as a result of activity under limited actions resource in solving the verbal and algorithmic problems. Fig. 5 shows the experimental dependence of the actions resource scope allocated by the system for each assignment on the number of the assignment completed (Nikolaeva, 2010) for different learners.

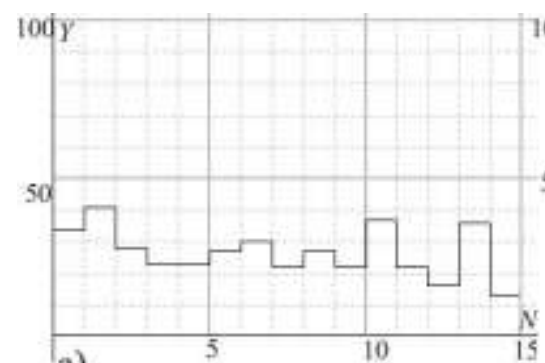

a)

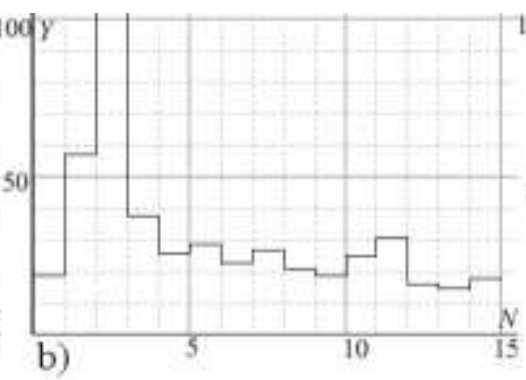

b)

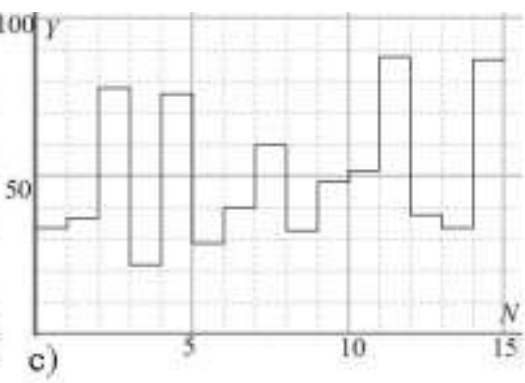

c)

Figure 5. Actions resource scope allocated by the system for solving the problem: a) for learner 1 ; b) for learner 2; c) for learner 3. $\mathrm{N}$ is the number of assignment and $\mathrm{Y}$ is the resource of actions.

These dependences allow concluding on what resource scope each learner needed for mastering the problem solving activity. From the dependence shown in Fig. 5a it is clear that learner 1 has reduced the scope of resource allocated for him by the automatic activity management system to the minimum necessary one after 2-3 assignments. It can be seen in Fig. $5 \mathrm{~b}$ that learner 2 needed a larger resource for solving the problems yet the scope was reduced after 6-8 assignments. Finally, from Fig. 5c it follows that 15 assignments were not enough for learner 3 to master this activity.

This time resource reduction results from the learners' achieving error-free activity in problem solving. The time needed for the activity is decreased approximating to a certain value of the optimum problem solving time.

1. The optimum activity tempo is not exactly predetermined by the external conditions but it is actively formed during self-adjustment. The information about the tested one's activity time resource spent for completion of $i$-th assignment and any change that is determined by previous $i$-1-th assignment time resource is especially significant.

2. The duration of the process of achieving the optimum time resource and its level largely depend on the extent of formation of self-adjustment mechanisms and the necessity to correct them in the course of activity. In order to ensure the efficiency of this process, temporal structure of the coherent activity should be optimized, the proportion of its cognitive and executive components should be modified, and the information attributes of learning activity 
should be restructured. The information basis of learning activity has a dynamic nature on balance and changes depending on the learning stages, which influences the temporal parameters of the activity.

The learners can benefit from this Web technology when studying various subjects, e.g. mathematics, Russian etc. By implementing the technology into the educational process, efficiency of learning can be enhanced and learning can be customized too.

\section{Conclusion}

The focus of the modern education and social trends render the research of the learners' cognitive characteristics relevant. The opportunities of the newest Web and mobile applications for diagnosing human individual abilities opened up lead to serious prospects of objectifying and giving the mass scale character to fast studies and a broad use of the users' computer diagnostics results.

In the paper, a novel projective cloud environment is suggested for diagnosing the individual and cognitive abilities, with studies, development and actual diagnostics of characteristics to be selected provided for in it. The feature of the website designed consists in its projective and recursive strategy that allows viewing the problem of expert statistics accumulation and user diagnostic results analysis in an integrated way. Meanwhile, any user is both a participant and a developer of the diagnosing environment. Some diagnostics are original and authored, containing artificial intelligence elements.

The initial set of diagnostics was selected in such a way because the methods of expert and statistical analysis of user results had to be applied. So, originally, the psychological diagnostics were selected for machine-assisted realization in conditions of a Web interface. The problemsolving environments and diagnosing toolkits were developed. Two categories of human abilities were also conceptually designed: the traditional principal cognitive characteristics - the scope of attention, the speed of calculation operations, reading, constructing actions etc.; and the integrated educational abilities - the level of learning, speed of learning, the ability to work under limited information and time resources.

It is useful to employ the opportunities of the website at classes and for the students performing their year and diploma papers. For instance, the students of Siberian Federal University and of Krasnoyarsk State Pedagogical University are engaged into both developing the website and conducting their own research. Similarly, teachers at pedagogical colleges of 
Minusinsk and Abakan teach their students to diagnose the citizens' cognitive abilities and to create their own diagnostics.

The website can be of use for educational institutions for integrated surveys of the learners. It can also be applied by HR workers of enterprises and businesses in order to identify the professional aptitude of employees and applicants.

To start work, use any browser to go to the website via the link http://self-test.ufoproger.ru and register on it. For creating one's own diagnostics, or for research, please contact the chief website administrator who will provide the rights and services as appropriate.

\section{Acknowledgements}

The authors express their gratitude to the regional foundation for science, as the work has been performed with the support of the Regional State Autonomous Institution "Krasnoyarsk regional foundation for support of science, scientific and engineering efforts" within the implementation of the project "Cloud technology of diagnosing the human cognitive abilities", 2017, code 2017031501764. 


\section{References}

Auvinen, T., Hakulinen, L. \& Malmi, L. (2015). Increasing Students' Awareness of Their Behavior in Online Learning Environments with Visualizations and Achievement Badges. IEEE Transactions on Learning Technologies, 8(3), 261-273.

Bazhenova, I.V. \& Pak N.I. (2016). Projective recursive technology of training in personally the focused education. Pedagogical Education in Russia, 7, 7-15.

Bloom, B.S., ed. (1956). Taxonomy of Educational Objectives: The Classification of Educational Goals; Handbook I: Cognitive Domain. New York: Longman.

Bortnovskiy, S.V. \& Diyachuk P.P. (jr), Nikolaeva, Yu.S. \& Surovtsev V.M. (2011). Computer system of optimization of a resource of educational actions. Open Education, 6, 9.

Bush, R. \& Mosteller, F. (1962). Stochastic models of learning ability. Moscow: Literature in Physics and Mathematics.

Clique, F. (1984). Studying of abilities: on the way to cognitive diagnostics of intelligence. Psychological Journal, 4, 14-28.

Cowgill II, D \& Waring, S . (2017). Historical Thinking: Analyzing Student and Teacher Ability to Analyze Sources. Journal of Social Studies Education Research, 8 (1), 115-145. Retrieved from http://dergipark.gov.tr/jsser/issue/29488/316360

Diyachuk, P.P., Nikolaeva, Yu.S. \& Pustovalov, L.V. (2010). Control system of the process of search of the solution of tasks in the conditions of restriction for resources. In: The controlling systems and machines, 2(226), 47-51,79.

Diamond, A. (2002). Normal development of prefrontal cortex from birth to young adulthood: cognitive functions, anatomy, and biochemistry. In: Stuss, D.T., Knight, R.T., eds. Principles of Frontal Lobe Function. London: Oxford University Press, 466-503.

Gentner, D, Holyoak, K.J., Kokinov, B.N., eds. (2001). The Analogical Mind: Perspectives from Cognitive Science. Cambridge, MA: MIT Press, 1-19.

Goswami, U. (2001). Analogical reasoning in children. In: Gentner, D., Holyoak, K.J., Kokinov, B.N., eds. The Analogical Mind: Perspectives from Cognitive Science. Cambridge, MA: MIT Press, 437-470.

Ines Reyes-Cespedes, P. \& Dominguez-Claro, Z. (2015). Diagnostic of the Information Technology in the disciplines related to Physics in the Mathematics-Physics career. LUZ, 4, 96-107. 
Jain, G.P., Gurupur, V.P., Schroeder, J.L. \& Faulkenberry, E.D. (2014). Artificial intelligencebased student learning evaluation: A concept map-based approach for analyzing a student's understanding of a topic. IEEE Transactions on Learning Technologies, 7(3), 267-279.

Jong, M.S.Y. (2016). Teachers' concerns about adopting constructivist online game-based learning in formal curriculum teaching: The visole experience. British Journal of Educational Technology, 47(4), 601-617.

Karpov, V.V. (1964). Signal programming of a time structure and the sequence of actions as a premise for self-checking in formation and regulation of personal speed. Psychology Questions, 2, 102-111.

Konopkin, O.A. (1980). Psychological mechanisms of regulation of activity. Moscow.

Klahr, D. \& Li, J.(2005). Cognitive research and elementary science instruction: from the laboratory, to the classroom, and back. Journal of Science Education and Technology, 4, 217-238.

Koedinger, K.R. \& Aleven, V. (2007). Exploring the assistance dilemma in experiments with cognitive tutors. Educational Psychology Review, 19, 239-264.

Krutka, D.G. \& Carano, K.T. (2017). Videoconferencing for Global Citizenship Education: Wise Practices for Social Studies Educators. Journal of Social Studies Education Research, 7(2), 109-136.

Kholonaya, M.A. (2000). Principles and methods of identification of exceptional children. In: Endowments: working concept / Resp. ed. D.B. Bogoyavlenskaya, B.D. Shadrikov. Moscow -Samara: RPO publishing house, 22-28.

Lishin, O.V., Krasnoplakhtova, L.I. \& Orlov, V.A. (1990). Diagnostics of the level of formation of socially useful activity as a way of psychological characterization of the educationalprocess. Psychological Journal, 2(4), 98-106.

Murillo, F.J. \& Hernandez-Castilla, R. (2015). Leadership for learning: What are the principals' tasks that most impact in the student learning? Relieve-revista electronica de investigacion y evaluacion educativa, 21(1), article number 1.

Nath, S. \& Szücs, D. (2014). Construction play and cognitive skills associated with the development of mathematical abilities in 7-year-old children. Learning and Instruction, 32, 73-80.

Nayser, U. (1981). Knowledge and reality. Moscow: Progress. 
Nikolaeva, Yu.S. (2012). Optimum operating time at the solution of tasks in verbal problem environments in the conditions of restriction for time resource. In: Modern problems of informatization in a modeoirovaniye and the sotsitsialnykh technologies: the collection of works following the results of the XVII international open scientific conference. Issue 17. Voronezh, 158-161.

Nikolaeva, Yu.S. (2010). Control system and diagnostics of educational activity in verbal problem environments. Control Systems and Information Technologies, 1.2(39), 259-263.

Novikov, D.A. (1998). Regularities of iterative learning. Moscow: Institute of the Problems of Contro 1, RAS.

Pak, N.I. (2014). Expert systems based on the mental scheme. In: XV Russian-Korean Scientific and Technical Conference. Ekaterinburg, Ural Federal University, 04 - 05 July, 233-235.

Pak, N.I. (2015). Visualization of information links in the information model of thinking. In: Works of the International Conference "2015 CIS-Korea Conference on Science and Technology". Moscow, 140-145.

Philipp, P., Fischer, Y., Hempel, D. \& Beyerer, Ju. (2015). Framework for an Interactive Assistance in Diagnostic Processes Based on the Translation of UML Activities into Petri Nets. International Conference on Computational Science and Computational Intelligence (CSCI). Las Vegas, 732-737.

Rassel, S. \& Norvig, P. (2006). Artificial intelligence: the modern approach. Moscow: Vilyams. Richland, L.E. \& Simms, N. (2015). Analogy, higher order thinking, and education. Wiley Interdisciplinary Reviews: Cognitive Science, 6(2), 177-192.

Tarling, I. \& Ng'ambi, D. (2016). Teachers pedagogical change framework: a diagnostic tool for changing teachers' uses of emerging technologies. British Journal of Educational Technology, 47(3), 554-572.

Tarman, B. (2016). Innovation and education. Research in Social Sciences and Technology, (1)1, 77-97.

Teplov, B.M. (1961). Problems of individual distinctions. Moscow.

von Aufschnaiter, C., Cappell, J. \& Duebbelde, G. (2015). Diagnostic competence theoretical considerations concerning a central construct of teacher education. Zeitschrift für Pädagogik, 61(5), 738-758. 
Waters, S. \& Russell, W.B. (2016). Virtually Ready? Pre-service teachers' perceptions of a virtual internship experience, Research in Social Sciences and Technology, (1)1, 1-23.

Wiegner, I. \& Willms, L. (1991). Activity-oriented process diagnostics among engineers of the deutsche-reichsbahn - validity tests under field conditions. Arbeitsmedizin, Sozialmedizin Präventivmedizin, 26(7), 269-289.

Wineburg, S.S. (1991). Historical problem solving: a study of the cognitive processes used in the evaluation of documentary and pictorial evidence. Journal of Educational Psychology, 83(1), 73.

Zhang, X.Y., Wang, S. \& Yun, X. (2015). Bidirectional active learning: A two-way exploration into unlabeled and labeled data set. IEEE Transactions on Neural Networks and Learning Systems, 26(12), 3034-3044. 